\title{
Preliminary Report for the Development of a Multiparameter Protocol for the Identification of Sinusoidal Obstruction Syndrome including Abdominal Ultrasound before and after Allogeneic Stem Cell Transplantation
}

\author{
Sebastian Schlaweck ${ }^{1,2,+} \mathbb{D}$, Claus Juergen Bauer ${ }^{1,+} \mathbb{D}$, Friederike Schmitz ${ }^{1}$, Peter Brossart ${ }^{1}$, \\ Tobias A. W. Holderried ${ }^{1, \ddagger}$ and Valentin Sebastian Schäfer ${ }^{1, *, \ddagger(D)}$ \\ 1 Medical Clinic III, Clinic for Oncology, Hematology, Immuno-Oncology and Rheumatology/Clinical \\ Immunology, University Hospital Bonn, Venusberg Campus 1, 53127 Bonn, Germany; \\ sebastian.schlaweck@ukbonn.de (S.S.); claus-juergen.bauer@ukbonn.de (C.J.B.); \\ friederike.schmitz@ukbonn.de (F.S.); peter.brossart@ukbonn.de (P.B.); \\ tobias.holderried@ukbonn.de (T.A.W.H.) \\ 2 Faculty of Medicine, Mildred Scheel School of Oncology Aachen Bonn Cologne Düsseldorf (MSSO ABCD), \\ University Hospital of Bonn, 53127 Bonn, Germany \\ * Correspondence: valentin.schaefer@ukbonn.de; Tel.: +49-228-22234; Fax: +49-228-22635 \\ + These authors contributed equally to this work. \\ $\ddagger$ These authors contributed equally to this work.
}

Citation: Schlaweck, S.; Bauer, C.J.; Schmitz, F.; Brossart, P.; Holderried, T.A.W.; Schäfer, V.S. Preliminary Report for the Development of a Multiparameter Protocol for the Identification of Sinusoidal Obstruction Syndrome including Abdominal Ultrasound before and after Allogeneic Stem Cell Transplantation. Appl. Sci. 2022, 12, 829. https://doi.org/10.3390/ app12020829

Academic Editor: Martin Oudega

Received: 30 November 2021

Accepted: 11 January 2022

Published: 14 January 2022

Publisher's Note: MDPI stays neutral with regard to jurisdictional claims in published maps and institutional affiliations.

Copyright: (C) 2022 by the authors. Licensee MDPI, Basel, Switzerland. This article is an open access article distributed under the terms and conditions of the Creative Commons Attribution (CC BY) license (https:// creativecommons.org/licenses/by/ $4.0 /)$.

\begin{abstract}
Sinusoidal obstruction syndrome (SOS) is a rare complication after allogeneic hematopoietic stem cell transplantation (alloHSCT) caused by endothelial dysfunction. Previous definitions and diagnostic criteria for the presence of SOS include bilirubinemia, hepatomegaly and weight gain, but histological evaluation is still the only way to prove the diagnosis of SOS. However, biopsy remains an invasive technique and is therefore undesirable in the alloHSCT scenario. Hence, a non-invasive diagnostic strategy is critical. Besides thorough clinical assessment and laboratory values, ultrasound examination remains part of the diagnostic workflow in clinical routine. Previous studies defined sonographic abnormalities, which are associated with the occurrence of SOS, but a standardized protocol to perform reliable abdominal ultrasound has not been finally defined. In this study, we evaluated a multi-parameter protocol including laboratory values as well as ultrasound examination pre- and post-alloHSCT. The application of this protocol was feasible in clinical practice and achieved a high inter- and intra-rater reliability. In our population, no case of SOS was identifiable and, in line with previous studies, no changes known to be associated with SOS were detected by ultrasound examination in our cohort. Additionally, we investigated subgroups of patients partly fulfilling SOS diagnostic criteria analyzing correlations between the fulfilled criteria and aberrances in ultrasound measurements pre- and post-alloHSCT. Although statistical examination may be limited by a small sample size and missing SOS cases, hyperbilirubinemia, thrombocytopenia and weight gain showed only a coincidence with selected, enlarged liver dimensions in few patients. This may underline the fact that hepatomegaly occurs as an unspecific finding after alloHSCT. Our protocol, including the ultrasound examination pre- and post-alloHSCT and laboratory parameters, may help to rule out SOS early, but validation in a greater population and different transplantation centers is required to warrant broader appliance. Nevertheless, we aim to contribute to an elaborate and standardized work-flow in peri-alloHSCT patient care.
\end{abstract}

Keywords: SOS; VOD; alloHSCT; gray-scale ultrasound

\section{Introduction}

Hematopoietic allogeneic stem cell transplantation (alloHSCT) is a potentially curative therapy for certain hematological diseases maintained by immunological control $[1,2]$. 
However, survival of patients undergoing alloHSCT is strongly affected by their comorbidities and organ function [3-5]. Besides relapse-related mortality, transplantrelated mortality (TRM) is a major concern [6]. TRM may be caused by allo-reactive T cells leading to massive tissue damage (Graft-versus-Host disease) [7], infections [8,9] or organ failure.

Veno-occlusive disease (VOD) or sinusoidal-obstructive-syndrome (SOS) is a rare but potentially life-threatening complication [10-13] with mortality rates above $65 \%$ in severe cases [14]. In SOS, occlusion of hepatic vessels is caused by the destruction of local endothelial cells following the conditioning regimen's toxicity [15]. Factors contributing to an increased risk of SOS have been reviewed recently [16], but diagnosis remains challenging. Among various diagnostic criteria proposed, the most commonly used parameters have been known as the Seattle and Baltimore criteria [17,18], whereas newer studies define modified diagnostic criteria [19]. Nonetheless, research groups like Carreras et al. questioned the reliability of these scores in the past as they seem to offer high specificity but low sensitivity [20]. In response, revised diagnostic criteria have been described by the European Society for Blood and Marrow Transplantation (EBMT) [21]. All these consider hepatomegaly, weight gain and increase of serum bilirubin within the first 3 weeks after transplant as diagnostic criteria.

Other clinical criteria potentially present in SOS are: Elevation of serum alanine aminotransferase (ALT), thrombocytopenia and consumption of transfused platelets, esophageal varices or signs of multi organ failure [22].

That background in mind, more accurate tools for diagnosis in clinical practice are required. Measurement of the hepatic venous gradient pressure has been acknowledged for its high diagnostic precision [23] but remains an invasive method. In contrast, ultrasound imaging as a non-invasive, reliable and easily accessible method, is recommended to exclude suspected SOS [24]. Pathological findings in abdominal ultrasound described to be associated with the diagnosis of SOS include: gallbladder wall thickening, reversal of portal vein blood flow, ascites, hepatomegaly as well as splenomegaly (as reviewed by Dignan et al. [24]). One study investigating the value of gray scale and Doppler ultrasound in the diagnosis of SOS attributed a high positive predictive value solely to a limited selection of parameters (positive predictive value $>80 \%$ only for identifiable ascites, visualization or flow record of the paraumbilical vein, and main portal vein flow reversal) [25]. Among these, only the flow recorded in the paraumbilical vein significantly correlated with the severity grade of SOS [26]. More recent reports have extended the data about sonographic changes in SOS patients by using more specific examinations like shear wave elastography, which has been described to be increased in SOS patients [27]. As this technique is not easily and broadly available, its use in clinical routine may be limited. In line with that, contrast-enhanced ultrasound (CEUS) was assessed in the context of SOS and pathologic examinations were associated with diagnostic criteria for SOS patients [28]. Recently revised criteria for grayscale ultrasound examination have been published, including sonographic measurements of the diameter of the following structures: the hepatic left lobe, hepatic right lobe, the gallbladder wall, the portal vein and the paraumbilical vein. Moreover, detection of ascites, a reduced flow velocity or even a flow congestion inside the portal vein, as well as an increased resistance index of the hepatic artery and detection of paraumbilical vein blood flow are of diagnostic relevance for SOS in this protocol [29]. A recent review [30] recommends measurement of all these parameters, named as HOKUS 10 [29], or those defined by Lassau in 1997 [25].

In this article, we present an abdominal ultrasound protocol for the identification of SOS incorporating all parameters described in previous studies, with the exception of those requiring contrast agents, maintaining optimal feasibility and reliability. Thereby, this protocol aims to define a standardized protocol in upcoming trials. Additionally, we investigated whether abnormalities in parameters traditionally serving as SOS diagnosis criteria (e.g., hyperbilirubinemia or weight gain) were associated with ultrasound abnormalities pre- and post-alloHSCT. 


\section{Methods}

\subsection{Patient Characteristics}

This prospective study included patients receiving an alloHSCT between September 2019 and September 2020 at the Clinic of Internal Medicine III, University Hospital Bonn, Germany. All patients included were adults ( $>18$ years old). Patient demographics and laboratory parameters (platelet count, C-reactive protein (CRP), aspartate aminotransferase (AST), alanine aminotransferase (ALT), gamma glutamyltransferase (yGT), alkaline phosphatase (AP) and bilirubin levels) were recorded before and after alloHSCT.

\subsection{Ultrasound Examination}

Ultrasound examinations were conducted by experienced ultrasonographers using an Alpinion E Cube (manufactured in 2019) with a 1-6 MHz curvilinear probe as a routine procedure before alloHSCT. Standard preset for abdominal ultrasound was used and adapted for each patient. The follow-up investigation post alloHSCT was performed either when there was clinical suspicion of SOS (indication by the head of the transplant unit, TAWH) or within 21 days after transplantation.

Spleen size was measured in sagittal and transversal diameter. We scanned for free fluid in three areas: the hepatorenal recess (Morison's pouch), the splenorenal recess, and the rectovesical or rectouterine space (Douglas pouch). Liver size evaluation contained measurements in the right mid-clavicular line, pre-renal as well as pre-aortic diameters. Flow and size of the hepatic portal vein and the proper hepatic artery were measured at the hepatic hilum. Resistance index of the hepatic artery was calculated. Liver vein measurements (flow curve, velocity and diameter) were performed at a two centimeters distance from their confluence, where they merge to form the inferior vena cava. Gallbladder wall thickness was determined at its thickest part. We scanned for reperfusion of the paraumbilical vein in the ligamentum teres hepatis (see Figure 1a,b for the illustration of all ultrasound scanning views applied).

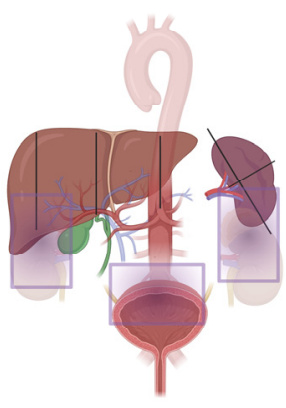

(a)

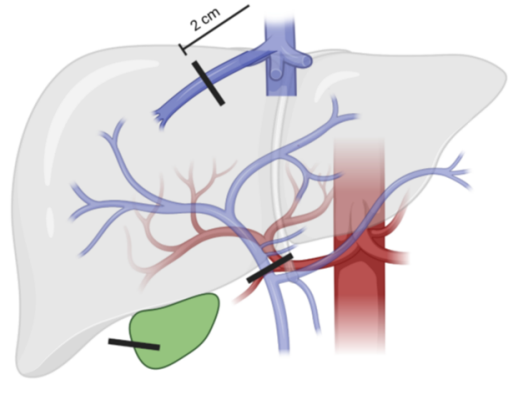

(b)

Figure 1. Schematic ultrasound scanning approach. Illustration of all ultrasound scanning axes applied within the SOS ultrasound protocol. Gray boxes represent areas scanned for ascites. Vertical lines show places for measurements as described in the methods section. Images were created with BioRender.com. $(\mathbf{a}, \mathbf{b})$ for the illustration of all ultrasound scanning views applied.

\subsection{Inter- and Intra-Rater Reliability}

To test inter- and intra-rater reliability, the ultrasonographers SS and FS each performed a reference ultrasound examination, as defined by the protocol (Supplemental File S1), of a healthy volunteer independently (after each other) on the identical two consecutive days.

\subsection{Statistical Analysis}

The statistic software $R$, version 4.0 .3 was used for statistical analysis [31]. All analyses shown are exploratory. Categorical data are presented in absolute and relative frequencies. Metric variables are summarized as mean \pm standard deviation (SD). Chi-square test was 
applied for comparison of categorical data. The distribution of variables was assessed graphically. When normality was assumable, a t-test was applied, otherwise a Wilcoxon test was used. In general, $p$-values presented with this publication are not adjusted for multiple testing (unless stated as such).

For categorical decisions, Cohen's kappa ( $\mathrm{k}$ ) coefficient was used to evaluate intraand inter-rater repeatability. For metric parameters, the Intraclass Correlation coefficient ICC [32] was used to evaluate intra- and inter-rater repeatability. ICC was rated according to the following classification: below 0.50: poor, between 0.50 and 0.75 : moderate, between 0.75 and 0.90: good, above 0.90: excellent.

\subsection{Ethics}

The study was conducted in accordance with the declaration of Helsinki and received ethical approval by the institutional ethics committee of the University of Bonn (IRB\#084/19). Written informed consent was obtained from every trial participant before inclusion.

\section{Results}

\subsection{Patient Population}

This investigation included 23 patients with a median age of 64 years (mean 61.8, range 19-79 years). Eight patients were female and 15 participants were male. Detailed patient characteristics are displayed in Table 1. Results of laboratory parameters and ultrasound measurements are listed in Tables 2 and 3. Baseline sonographic measurements were conducted a median of 29 days (mean 35 days (range: 2-104 days)) before the day of transplantation; laboratory values and patient characteristics from the same day were used for further analysis. The second ultrasound examination was performed a median of 9 days (mean: 10.43 days (range 5-27 days)) after alloHSCT; laboratory values and patient characteristics were recorded on the same day after alloHSCT. No patient was diagnosed with SOS.

Table 1. Patient Characteristics.

\begin{tabular}{|c|c|}
\hline Patient Characteristics & $(N=23)$ \\
\hline \multicolumn{2}{|l|}{ Age } \\
\hline Mean (SD) & $61.8(12.8)$ \\
\hline Median [Min, Max] & $64.0[19.0,79.0]$ \\
\hline \multicolumn{2}{|l|}{ Sex } \\
\hline Female & $8(34.8 \%)$ \\
\hline Male & $15(65.2 \%)$ \\
\hline \multicolumn{2}{|l|}{ Weight } \\
\hline Mean (SD) & $79.9(17.5)$ \\
\hline Median [Min, Max] & $78.0[45.4,119]$ \\
\hline \multicolumn{2}{|l|}{ Disease } \\
\hline Leukemia & $15(65 \%)$ \\
\hline Multiple myeloma & $1(4.3 \%)$ \\
\hline Myelodysplastic syndrome & $6(26 \%)$ \\
\hline Myeloproliferative syndrome & $1(4.3 \%)$ \\
\hline \multicolumn{2}{|l|}{ Conditioning regimen } \\
\hline Myeloablative & $1(4.3 \%)$ \\
\hline Non-myeloablative & $22(95.7 \%)$ \\
\hline \multicolumn{2}{|l|}{ AlloHSCT donor compatibility } \\
\hline Matched unrelated donor & $15(65.21 \%)$ \\
\hline Mismatch unrelated donor & $3(13.04 \%)$ \\
\hline Matched related donor & $2(8.69 \%)$ \\
\hline Haploidentical related donor & $3(13.04 \%)$ \\
\hline \multicolumn{2}{|l|}{ Peritransplantational findings } \\
\hline Presence of fever & $19(82.61 \%)$ \\
\hline Abdominal pain & $7(30.43 \%)$ \\
\hline Body weight increase $>2 \%$ & $9(39.13 \%)$ \\
\hline
\end{tabular}


Table 2. Laboratory Parameters.

\begin{tabular}{|c|c|c|c|}
\hline & $\begin{array}{c}\text { Pre } \\
(\mathrm{N}=23)\end{array}$ & $\begin{array}{c}\text { Post } \\
(\mathrm{N}=23)\end{array}$ & $p$ Value \\
\hline \multicolumn{4}{|l|}{ CRP (mg/L) } \\
\hline Mean (SD) & $22.1(36.1)$ & $61.4(79.0)$ & \multirow{2}{*}{0.0091} \\
\hline Median [Min, Max] & $3.71[0.340,125]$ & $46.0[0.600,296]$ & \\
\hline \multicolumn{4}{|l|}{ Bilirubin (mg/dL) } \\
\hline Mean (SD) & $0.641(0.837)$ & $2.96(3.86)$ & \multirow[t]{2}{*}{0.0001} \\
\hline Median [Min, Max] & $0.420[0.200,4.36]$ & $2.56[0.330,19.4]$ & \\
\hline \multicolumn{4}{|l|}{ AP (U/L) } \\
\hline Mean (SD) & 154 (117) & $110(61.3)$ & \multirow[t]{3}{*}{0.36} \\
\hline Median [Min, Max] & $99.0[35.0,376]$ & $92.0[35.0,297]$ & \\
\hline Missing & $1(4.3 \%)$ & $0(0 \%)$ & \\
\hline \multicolumn{4}{|l|}{ AST (U/L) } \\
\hline Mean (SD) & $34.3(23.6)$ & $26.7(26.6)$ & \multirow[t]{2}{*}{0.048} \\
\hline Median [Min, Max] & $29.0[8.00,120]$ & $18.0[7.00,138]$ & \\
\hline \multicolumn{4}{|l|}{ ALT $(U / L)$} \\
\hline Mean (SD) & $53.3(56.5)$ & $28.3(24.3)$ & \multirow[t]{2}{*}{0.0031} \\
\hline Median [Min, Max] & $44.0[5.00,267]$ & $21.0[5.00,113]$ & \\
\hline \multicolumn{4}{|l|}{$\gamma \mathrm{GT}(\mathrm{U} / \mathrm{L})$} \\
\hline Mean (SD) & $168(186)$ & $114(91.1)$ & \multirow[t]{2}{*}{0.12} \\
\hline Median [Min, Max] & $101[10.0,745]$ & $80.0[0.680,280]$ & \\
\hline \multicolumn{4}{|l|}{ Thrombocytes (G/L) } \\
\hline Mean (SD) & 140 (124) & $45.8(58.8)$ & \multirow[t]{2}{*}{0.0051} \\
\hline Median [Min, Max] & $102[11.0,395]$ & $24.0[7.00,260]$ & \\
\hline
\end{tabular}

Pre = median 29 days before hematopoietic allogeneic stem cell transplantation, post = median 9 days after hematopoietic allogeneic stem cell transplantation, laboratory parameters measured at the day of ultrasound examination. AP: alkaline phosphatase, AST: aspartate aminotransferase, ALT: alanine aminotransferase, $\gamma \mathrm{GT}$ : gamma-glutamyl transferase.

Table 3. Sonography Measurements.

\begin{tabular}{|c|c|c|}
\hline & $\begin{array}{c}\text { Pre } \\
(\mathrm{N}=23)\end{array}$ & $\begin{array}{c}\text { Post } \\
(\mathrm{N}=23)\end{array}$ \\
\hline \multicolumn{3}{|l|}{ Ultrasound of the liver } \\
\hline \multicolumn{3}{|c|}{ Vertical diameter-pre-aortic measurement } \\
\hline Mean (SD) & $9.55(2.53)$ & $10.3(2.94)$ \\
\hline Median [Min, Max] & $9.65[5.30,15.5]$ & $10.2[4.10,15.0]$ \\
\hline Missing & $1(4.3 \%)$ & $1(4.3 \%)$ \\
\hline \multicolumn{3}{|c|}{ Vertical diameter-medio-clavicular line } \\
\hline Mean (SD) & $15.1(3.68)$ & $16.5(2.99)$ \\
\hline Median [Min, Max] & $15.1[7.60,25.0]$ & $16.9[10.6,22.0]$ \\
\hline Missing & $1(4.3 \%)$ & $0(0 \%)$ \\
\hline \multicolumn{3}{|c|}{ Vertical diameter-pre-renal measurement } \\
\hline Mean (SD) & $15.1(3.13)$ & $16.3(2.78)$ \\
\hline Median [Min, Max] & $15.1[8.10,21.0]$ & $17.1[10.5,21.7]$ \\
\hline Missing & $1(4.3 \%)$ & $1(4.3 \%)$ \\
\hline \multicolumn{3}{|c|}{ Maximal thickness of gallbladder } \\
\hline Mean (SD) & $0.256(0.0934)$ & $0.314(0.0954)$ \\
\hline Median [Min, Max] & $0.250[0,0.400]$ & $0.310[0.100,0.430]$ \\
\hline Missing & $3(13.0 \%)$ & $5(21.7 \%)$ \\
\hline \multicolumn{3}{|c|}{ Ultrasound of hepatic vessels } \\
\hline \multicolumn{3}{|c|}{ Maximal diameter of liver veins } \\
\hline Mean (SD) & $0.752(0.267)$ & $0.868(0.312)$ \\
\hline Median [Min, Max] & $0.700[0.370,1.20]$ & $0.850[0.200,1.90]$ \\
\hline Missing & $0(0 \%)$ & $0(0 \%)$ \\
\hline \multicolumn{3}{|c|}{ Maximal velocity of liver veins } \\
\hline Mean (SD) & $17.9(7.77)$ & $17.9(9.99)$ \\
\hline Median [Min, Max] & $17.8[5.00,37.1]$ & $16.3[0,30.9]$ \\
\hline Missing & $4(17.4 \%)$ & $14(60.9 \%)$ \\
\hline
\end{tabular}


Table 3. Cont.

\begin{tabular}{|c|c|c|}
\hline & $\begin{array}{c}\text { Pre } \\
(\mathrm{N}=23)\end{array}$ & $\begin{array}{c}\text { Post } \\
(\mathrm{N}=23)\end{array}$ \\
\hline \multicolumn{3}{|c|}{ Hepatopetal flow of liver veins } \\
\hline No & $23(100 \%)$ & $23(100 \%)$ \\
\hline Yes & $0(0 \%)$ & $0(0 \%)$ \\
\hline Missing & $0(0 \%)$ & $0(0 \%)$ \\
\hline \multicolumn{3}{|c|}{ Maximal diameter of portal vein } \\
\hline Mean (SD) & $0.963(0.227)$ & $1.01(0.295)$ \\
\hline Median [Min, Max] & $0.900[0.600,1.40]$ & $0.980[0.500,1.80]$ \\
\hline Missing & $3(13.0 \%)$ & $1(4.3 \%)$ \\
\hline \multicolumn{3}{|c|}{ Maximal velocity of portal vein } \\
\hline Mean (SD) & $17.8(14.0)$ & $18.2(11.7)$ \\
\hline Median [Min, Max] & $16.3[0.700,69.6]$ & $15.2[6.20,57.0]$ \\
\hline Missing & $1(4.3 \%)$ & $3(13.0 \%)$ \\
\hline \multicolumn{3}{|c|}{ Hepatopetal flow of portal vein } \\
\hline No & $0(0 \%)$ & $0(0 \%)$ \\
\hline Yes & $23(100 \%)$ & $22(95.7 \%)$ \\
\hline Missing & $0(0 \%)$ & $1(4.3 \%)$ \\
\hline \multicolumn{3}{|l|}{ Hepatic artery RI } \\
\hline Mean (SD) & $0.805(0.186)$ & $0.831(0.125)$ \\
\hline Median [Min, Max] & $0.795[0.400,1.10]$ & $0.830[0.470,1.00]$ \\
\hline Missing & $3(13.0 \%)$ & $2(8.7 \%)$ \\
\hline \multicolumn{3}{|c|}{ Ultrasound of the spleen } \\
\hline \multicolumn{3}{|l|}{ Spleen length } \\
\hline Mean (SD) & $12.9(3.58)$ & $12.6(2.66)$ \\
\hline Median [Min, Max] & $12.0[8.40,24.2]$ & $12.1[7.50,18.3]$ \\
\hline Missing & $0(0 \%)$ & $2(8.7 \%)$ \\
\hline \multicolumn{3}{|l|}{ Spleen width } \\
\hline Mean (SD) & $4.99(1.53)$ & $5.39(1.33)$ \\
\hline Median [Min, Max] & $4.40[3.60,10.0]$ & $5.18[3.40,8.40]$ \\
\hline Missing & $1(4.3 \%)$ & $3(13.0 \%)$ \\
\hline \multicolumn{3}{|c|}{ Ultrasound of the abdominal cavity } \\
\hline \multicolumn{3}{|c|}{ Pathologic recanalization of umbilical vein } \\
\hline No & $23(100 \%)$ & $22(95.7 \%)$ \\
\hline Yes & $0(0 \%)$ & $0(0 \%)$ \\
\hline Missing & $0(0 \%)$ & $1(4.3 \%)$ \\
\hline \multicolumn{3}{|l|}{ Ascites } \\
\hline No & $22(95.7 \%)$ & $19(82.6 \%)$ \\
\hline Yes & $1(4.3 \%)$ & $4(17.4 \%)$ \\
\hline Missing & $0(0 \%)$ & $0(0 \%)$ \\
\hline
\end{tabular}

We observed a significant decrease in AST (34.3 U/L pre, $26.7 \mathrm{U} / \mathrm{L}$ post; $p=0.048$ ) and ALT (53.3 U/L pre, $28.3 \mathrm{U} / \mathrm{L}$ post; $p=0.0031)$ during the course of allogeneic stem cell transplantation. Thrombocyte counts $(140 \mathrm{G} / \mathrm{L}$ pre, $45.8 \mathrm{G} / \mathrm{L}$ post; $p=0.0051)$ were also considerably reduced after alloHSCT. Moreover, a significant increase in bilirubin $(0.6 \mathrm{mg} / \mathrm{dL}$ pre, $2.96 \mathrm{mg} / \mathrm{dL}$ post, $p=0.0001)$ and CRP $(22.1 \mathrm{mg} / \mathrm{L}$ pre, $61.4 \mathrm{mg} / \mathrm{L}$ post; $p=0.0091)$ levels was noted after alloHSCT. Levels of $\gamma \mathrm{GT}(168 \mathrm{U} / \mathrm{L}$ pre, $114 \mathrm{U} / \mathrm{L}$ post; $p=0.12)$ and $\mathrm{AP}(154 \mathrm{U} / \mathrm{L}$ pre, $110 \mathrm{U} / \mathrm{L}$ post; $p=0.36)$ remained statistically unchanged.

Presence of fever throughout the course of alloHSCT (defined as measurable body temperature $\geq 38.5$ degrees Celsius within the timespan of the alloHSCT inpatient stay) occurred in 19 out of 23 patients. In most cases, this was temporally correlated with the administration of anti-thymocyte-globulin $(n=10)$ or intravenous immunoglobulins $(n=2)$. In fewer cases fever was interpreted as a sign of infection.

In seven out of 23 patients, abdominal pain was recorded during the peritransplantperitransplant period. Four cases were interpreted as painful hepatomegaly, one case showed CT-proven mild appendicitis, in one case computer tomography revealed an incomplete 
paralytic ileus at the recto-sigmoid junction, and one patient showed self-limiting signs of gastritis. An increase in body weight greater than two percent between both ultrasound examinations was observed in nine out of 23 trial participants.

When comparing ultrasound measurements pre- and post-alloHSCT, a significant increase in the maximum diameter of the liver veins was detected $(0.75 \mathrm{~cm}$ pre, $0.86 \mathrm{~cm}$ post; $p=0.038$ ). Regarding further ultrasound parameters, we did not find statistically significant changes.

Because hyperbilirubinemia and weight gain are required for the diagnosis of SOS, we investigated whether we can identify changes of ultrasound findings in these specific two subgroups by comparing their pre- and post-alloHSCT examination. As thrombocytopenia is reported to be associated with higher probability of SOS [22] as well, we investigated this subgroup (defined by thrombocytes $\leq 20 \mathrm{G} / \mathrm{L}$ at the day of the second ultrasound examination) additionally. Groups for the other previously described risk factors (e.g., ALT elevation) were too small to be investigated. However, in the investigated subgroups we rarely observed any significant changes in ultrasound parameters. Comparing the difference in measurements between pre- and post-alloHSCT examination within those subgroups, an increase in vertical diameter of the liver showed significant changes. In detail this could be shown for the pre-aortically measured vertical diameter of the liver, when comparing patients with thrombocyte counts of above $20 \mathrm{G} / \mathrm{L}$ vs. $\leq 20 \mathrm{G} / \mathrm{L}$ after transplantation ( $p=0.039$; adjusted for multiple testing). Moreover, an increase of the vertical liver diameter in pre-renal measurement was statistically significant comparing patients with respect to their bodyweight gain of above vs. below two percent $(p=0.0199$; adjusted for multiple testing).

\subsection{Inter-Rater and Intra-Rater Reliability Exercise}

Reliability exercise was performed as described before. Intra-rater reliability was 0.997 and 0.968 , respectively. Inter-rater reliability was 0.873 for the first and 0.916 for the second examination.

\section{Discussion}

Although various diagnostic criteria have been published $[17,19,21,33,34]$ the diagnosis of SOS is still challenging. SOS remains a clinical diagnosis until proven by biopsy. For a long time, ultrasound examinations have been used to rule out SOS rather than to confirm its presence [24]. Nevertheless, novel scoring systems have been developed to diagnose SOS by ultrasound including a selection of 10 sonographic parameters (HOKUS-10) [29]. These parameters have been refined recently [35] and the diagnosis of SOS by ultrasound was called "confirmed" when ascites was present and two of the following six findings were detected at the same time: moderate amount of ascites, the appearance of a paraumbilical vein blood flow signal, gallbladder wall thickening, portal vein dilatation, portal vein velocity decrease, and hepatic artery resistive index increase [35].

In summary, standardized ultrasound protocols for SOS investigation may help to facilitate diagnosis. We included laboratory as well as ultrasound values and present the first study to incorporate all published parameters into a comprehensive SOS ultrasound protocol.

In our study population of 23 patients, no case of SOS was detected, but we observed significant changes in laboratory parameters comparing them pre- and post-alloHSCT.

Results from this study showed a significant increase in bilirubin levels after allogeneic transplantation, which may be explained in part by the design of our study protocol, in which patients were scheduled for a second ultrasound evaluation when their bilirubin level rose or when their timeline approached day 21 following transplantation. Few patients without bilirubin increase or clinical suspicion of SOS missed their second ultrasound examination and needed to be excluded from the analysis, which leads to a slight tilt of the study population. Other reasons for hyperbilirubinemia besides SOS (where a bilirubin level greater than $2 \mathrm{mg}$ / dL is a diagnostic criterion [33]) have to be taken into account, such 
as toxic effects of the conditioning regimen and other drug toxicities, e.g., anti-thymocyteglobulin-induced hyperbilirubinemia [34-36]. In this study, $65.21 \%$ (15 out of 23 ) of the enrolled patients received anti-thymocyte-globulin (ATG), which may have contributed to increased bilirubin levels in our cohort. However, as bilirubinemia serves as a diagnostic criterion for SOS, we kept this parameter as part of the protocol. The reasonability of this approach is emphasized by results of a recent study that reported a correlation between early bilirubinemia (cut off defined at $3.6 \mathrm{mg} / \mathrm{dL}$ ) and increased non-relapse mortality independent of SOS [37]. Again, this fact may highlight the importance to monitor bilirubin levels with caution.

Other changes in laboratory parameters observed in our study may also be explained by transplant-related side effects. For example, application of ATG or transplant-related infections may contribute to increased CRP levels as observed in our population [38].

Patients in our study had a median thrombocyte count of $24 \mathrm{G} / \mathrm{L}$ at the day of their ultrasound examination after alloHSCT, which was markedly decreased compared to values before transplantation, owing mostly to the conditioning regimen and aplasia that is prevalent following alloHSCT. Even though clinical separation from thrombocytopenia related to other reasons can be tough, increased consumption of thrombocytes may be observed in SOS [22], and therefore we included platelet count evaluation in our protocol.

In line with a previously published study [39], which described an elevation of the liver enzymes ALT and AST higher than grade 3 (according to CTCAE v5.0) to be very rare after alloHSCT, we observed even a decrease in the level of these enzymes in our cohort. Therefore, being less confounded by other factors, AST and ALT levels may serve as a favorable surrogate marker for liver damage in general and SOS specifically, provided that veno-occlusive disease is rather associated with increased ALT levels [22].

The only statistically significant sonographical change between pre- and post-alloHSCT examination found in our study was an increase in the diameter of the hepatic vein. In contrast, Lassau et al. identified a hepatic vein diameter reduction to less than $3 \mathrm{~mm}$ to be specific for SOS (93\% specificity) [25]. Given that none of our patients showed signs of SOS, our observation is in line with previous literature. Furthermore, as expected in a cohort without SOS occurrence, we were not able to detect any other significant changes by ultrasound examination. Nevertheless, the limited sample size may contribute to missing significant changes. To our knowledge, we are the first to report a protocol including pre-alloHSCT examination and to note changes in these parameters.

In order to underline the predictive impact of regular results from ultrasound examination in patients without SOS we examined subgroups of patients partly fulfilling non-ultrasound diagnostic criteria for SOS or showing signs associated with an increased risk of SOS. Here we compared the differences between pre- and post-alloHSCT examination. In detail, we performed three separate subgroup analyses each dividing our patient collective into two groups by applying a cutoff regarding either weight gain $(>2 \%$ vs. $<2 \%)$, thrombocyte count post alloHSCT $(<$ or $>0 \mathrm{G} / \mathrm{L}$ ), or bilirubin level post-alloHSCT $(<$ or $>2 \mathrm{mg} / \mathrm{dL}$ ). Considering our SOS-free cohort, only changes regarding the hepatic size were detectable. Remarkably, in all cases, we only detected a significant increase in hepatic diameter in one out of three measured dimensions, which calls this finding into question in general. Nevertheless, hepatomegaly has its place as ultrasound criterion with low specificity for SOS and should be monitored with caution [25,40].

In this protocol, already published ultrasound as well as laboratory and clinical parameters known to be associated with the occurrence of SOS are summarized in a standardized and reproducible work-flow. Statistical analysis, which may be limited by the number of patients included and the lack of any SOS case, was in line with previous published findings in SOS. Nevertheless, to warrant additional validation of this protocol, evaluation of our approach, including pre- and post-alloHSCT laboratory, clinical and ultrasound examination, is needed in additional transplant centers with larger patient populations.

Our protocol introduced with this publication achieved good to excellent [32] interand intra-rater reliability, which emphasizes the reliability of abdominal ultrasound in 
clinical practice. We were able to validate a protocol for the exclusion of SOS after alloHSCT incorporating all published parameters. The protocol has already been implemented as an integral part of our peri-alloHSCT management-applied before alloHSCT as part of our screening examinations and after alloHSCT whenever evaluation due to SOS suspicion is necessary. With this protocol, we aim to exclude SOS early and accurately in order to improve patient survival. Additional validation at multiple transplantation centers with larger patient cohorts may underline its significance.

Supplementary Materials: The following supporting information can be downloaded at: https: //www.mdpi.com/article/10.3390/app12020829/s1, Data form of the used protocol is attached as Supplementary File.

Author Contributions: S.S., V.S.S. and T.A.W.H. designed the study. S.S. and F.S. performed ultrasound examination. C.J.B. was responsible for data management and statistical evaluation. S.S., C.J.B., V.S.S., T.A.W.H. and P.B. wrote the manuscript and discussed the data. All authors have read and agreed to the published version of the manuscript.

Funding: This work was funded by the Deutsche Krebshilfe through a Mildred Scheel Nachwuchszentrum Grant (Grant number 70113307 to S.S.)

Institutional Review Board Statement: The study was conducted in accordance with the declaration of Helsinki and received ethical approval by the institutional ethics committee of the University of Bonn (IRB\#084/19).

Informed Consent Statement: Informed consent was obtained from all subjects involved in the study.

Data Availability Statement: Data is available upon request to corresponding author.

Conflicts of Interest: The authors declare no conflict of interest.

\section{References}

1. Thomas, E.D.; Lochte, H.L.; Lu, W.C.; Ferrebee, J.W. Intravenous Infusion of Bone Marrow in Patients Receiving Radiation and Chemotherapy. N. Engl. J. Med. 1957, 257, 491-496. [CrossRef]

2. Weiden, P.L.; Flournoy, N.; Thomas, E.D.; Prentice, R.; Fefer, A.; Buckner, C.D.; Storb, R. Antileukemic Effect of Graft-versus-Host Disease in Human Recipients of Allogeneic-Marrow Grafts. N. Engl. J. Med. 1979, 300, 1068-1073. [CrossRef] [PubMed]

3. Sorror, M.L.; Maris, M.B.; Storb, R.; Baron, F.; Sandmaier, B.M.; Maloney, D.G.; Storer, B. Hematopoietic Cell Transplantation (HCT)Specific Comorbidity Index: A New Tool for Risk Assessment before Allogeneic HCT. Blood 2005, 106, 2912-2919. [CrossRef] [PubMed]

4. Sorror, M.L.; Sandmaier, B.M.; Storer, B.E.; Maris, M.B.; Baron, F.; Maloney, D.G.; Scott, B.L.; Deeg, H.J.; Appelbaum, F.R.; Storb, R. Comorbidity and Disease Status-Based Risk Stratification of Outcomes Among Patients With Acute Myeloid Leukemia or Myelodysplasia Receiving Allogeneic Hematopoietic Cell Transplantation. J. Clin. Oncol. 2007, 25, 4246-4254. [CrossRef]

5. Luft, T.; Benner, A.; Terzer, T.; Jodele, S.; Dandoy, C.E.; Storb, R.; Kordelas, L.; Beelen, D.; Gooley, T.; Sandmaier, B.M.; et al. EASIX and Mortality after Allogeneic Stem Cell Transplantation. Bone Marrow Transplant. 2020, 55, 553-561. [CrossRef] [PubMed]

6. D'Souza, A.; Fertham, C. Current Uses and Outcomes of Hematopoietic Cell Transplantation (HCT): CIBMTR Summary Slides. 2017. Available online: http:/ /www.cibmtr.org (accessed on 23 November 2021).

7. Zeiser, R.; Blazar, B.R. Acute Graft-versus-Host Disease-Biologic Process, Prevention, and Therapy. N. Engl. J. Med. 2017, 377, 2167-2179. [CrossRef] [PubMed]

8. Sahin, U.; Toprak, S.K.; Atilla, P.A.; Atilla, E.; Demirer, T. An Overview of Infectious Complications after Allogeneic Hematopoietic Stem Cell Transplantation. J. Infect. Chemother. 2016, 22, 505-514. [CrossRef] [PubMed]

9. Wingard, J.R.; Hsu, J.; Hiemenz, J.W. Hematopoietic Stem Cell Transplantation: An Overview of Infection Risks and Epidemiology. Hematol. Oncol. Clin. N. Am. 2011, 25, 101-116. [CrossRef]

10. Bearman, S. The Syndrome of Hepatic Veno-Occlusive Disease after Marrow Transplantation. Blood 1995, 85, 3005-3020. [CrossRef] [PubMed]

11. Richardson, P.G.; Murakami, C.; Jin, Z.; Warren, D.; Momtaz, P.; Hoppensteadt, D.; Elias, A.D.; Antin, J.H.; Soiffer, R.; Spitzer, T.; et al. Multi-Institutional Use of Defibrotide in 88 Patients after Stem Cell Transplantation with Severe Veno-Occlusive Disease and Multisystem Organ Failure: Response without Significant Toxicity in a High-Risk Population and Factors Predictive of Outcome. Blood 2002, 100, 4337-4343. [CrossRef] [PubMed]

12. Richardson, P.; Guinan, E. The Pathology, Diagnosis, and Treatment of Hepatic Veno-Occlusive Disease: Current Status and Novel Approaches. Br. J. Haematol. 1999, 107, 485-493. [CrossRef] 
13. Coppell, J.A.; Richardson, P.G.; Soiffer, R.; Martin, P.L.; Kernan, N.A.; Chen, A.; Guinan, E.; Vogelsang, G.; Krishnan, A.; Giralt, S.; et al. Hepatic Veno-Occlusive Disease Following Stem Cell Transplantation: Incidence, Clinical Course, and Outcome. Biol. Blood Marrow Transplant. J. Am. Soc. Blood Marrow Transplant. 2010, 16, 157-168. [CrossRef]

14. Carreras, E.; Bertz, H.; Arcese, W.; Vernant, J.-P.; Tomás, J.-F.; Hagglund, H.; Bandini, G.; Esperou, H.; Russell, J.; de la Rubia, J.; et al. Incidence and Outcome of Hepatic Veno-Occlusive Disease After Blood or Marrow Transplantation: A Prospective Cohort Study of the European Group for Blood and Marrow Transplantation. Blood 1998, 92, 3599-3604.

15. Fan, C.Q.; Crawford, J.M. Sinusoidal Obstruction Syndrome (Hepatic Veno-Occlusive Disease). J. Clin. Exp. Hepatol. 2014, 4, 332-346. [CrossRef]

16. Dalle, J.-H.; Giralt, S.A. Hepatic Veno-Occlusive Disease after Hematopoietic Stem Cell Transplantation: Risk Factors and Stratification, Prophylaxis, and Treatment. Biol. Blood Marrow Transplant. 2016, 22, 400-409. [CrossRef] [PubMed]

17. Jones, R.J.; Lee, K.S.; Beschorner, W.E.; Vogel, V.G.; Grochow, L.B.; Braine, H.G.; Vogelsang, G.B.; Sensenbrenner, L.L.; Santos, G.W.; Saral, R. Venoocclusive Disease of the Liver Following Bone Marrow Transplantation. Transplantation 1987, 44, 778-783. [CrossRef] [PubMed]

18. Shulman, H.M.; Hinterberger, W. Hepatic Veno-Occlusive Disease-Liver Toxicity Syndrome after Bone Marrow Transplantation. Bone Marrow Transplant. 1992, 10, 197-214. [PubMed]

19. Corbacioglu, S.; Carreras, E.; Ansari, M.; Balduzzi, A.; Cesaro, S.; Dalle, J.-H.; Dignan, F.; Gibson, B.; Guengoer, T.; Gruhn, B.; et al. Diagnosis and Severity Criteria for Sinusoidal Obstruction Syndrome/Veno-Occlusive Disease in Pediatric Patients: A New Classification from the European Society for Blood and Marrow Transplantation. Bone Marrow Transplant. 2018, 53, 138-145. [CrossRef]

20. Carreras, E.; Grañena, A.; Navasa, M.; Bruguera, M.; Marco, V.; Sierra, J.; Tassies, M.D.; García-Pagán, J.C.; Martí, J.M.; Bosch, J.; et al. On the Reliability of Clinical Criteria for the Diagnosis of Hepatic Veno-Occlusive Disease. Ann. Hematol. 1993, 66, 77-80. [CrossRef]

21. Mohty, M.; Malard, F.; Abecassis, M.; Aerts, E.; Alaskar, A.S.; Aljurf, M.; Arat, M.; Bader, P.; Baron, F.; Bazarbachi, A.; et al. Revised Diagnosis and Severity Criteria for Sinusoidal Obstruction Syndrome/Veno-Occlusive Disease in Adult Patients: A New Classification from the European Society for Blood and Marrow Transplantation. Bone Marrow Transplant. 2016, 51, 906-912. [CrossRef]

22. Carreras, E. How I Manage Sinusoidal Obstruction Syndrome after Haematopoietic Cell Transplantation. Br. J. Haematol. 2015, 168, 481-491. [CrossRef] [PubMed]

23. Carreras, E.; Grañena, A.; Navasa, M.; Bruguera, M.; Marco, V.; Sierra, J.; Tassies, M.D.; García-Pagán, J.C.; Martí, J.M.; Bosch, J. Transjugular Liver Biopsy in BMT. Bone Marrow Transplant. 1993, 11, 21-26. [PubMed]

24. Dignan, F.L.; Wynn, R.F.; Hadzic, N.; Karani, J.; Quaglia, A.; Pagliuca, A.; Veys, P.; Potter, M.N. BCSH/BSBMT Guideline: Diagnosis and Management of Veno-Occlusive Disease (Sinusoidal Obstruction Syndrome) Following Haematopoietic Stem Cell Transplantation. Br. J. Haematol. 2013, 163, 444-457. [CrossRef]

25. Lassau, N.; Leclère, J.; Auperin, A.; Bourhis, J.H.; Hartmann, O.; Valteau-Couanet, D.; Benhamou, E.; Bosq, J.; Ibrahim, A.; Girinski, T.; et al. Hepatic Veno-Occlusive Disease after Myeloablative Treatment and Bone Marrow Transplantation: Value of Gray-Scale and Doppler US in 100 Patients. Radiology 1997, 204, 545-552. [CrossRef]

26. Lassau, N.; Auperin, A.; Leclere, J.; Bennaceur, A.; Valteau-couanet, D.; Hartmann, O. Prognostic Value of DopplerUltrasonography in Hepatic Veno-Occlusive Disease: A Study of 71 Children. Transplantation 2002, 74, 60-66. [CrossRef]

27. Schulz, M.; Vuong, L.G.; Müller, H.P.; Maibier, M.; Tacke, F.; Blau, I.W.; Wree, A. Shear Wave Elastography in the Detection of Sinusoidal Obstruction Syndrome in Adult Patients Undergoing Allogenic Hematopoietic Stem Cell Transplantation. Diagnostics 2021, 11, 928. [CrossRef] [PubMed]

28. Trenker, C.; Burchert, A.; Schumacher, C.; Schäfer, J.A.; Dohse, M.; Timmesfeld, N.; Neubauer, A.; Sohlbach, K.; Michel, C.; Görg, C. Pathologic Hepatic Contrast-Enhanced Ultrasound Pattern in Patients Undergoing Allogeneic Stem Cell Transplantation. Ultrasound Med. Biol. 2020, 46, 1865-1871. [CrossRef]

29. Nishida, M.; Kahata, K.; Hayase, E.; Shigematsu, A.; Sato, M.; Kudo, Y.; Omotehara, S.; Iwai, T.; Sugita, J.; Shibuya, H.; et al. Novel Ultrasonographic Scoring System of Sinusoidal Obstruction Syndrome after Hematopoietic Stem Cell Transplantation. Biol. Blood Marrow Transplant. 2018, 24, 1896-1900. [CrossRef]

30. Chan, S.S.; Colecchia, A.; Duarte, R.F.; Bonifazi, F.; Ravaioli, F.; Bourhis, J.H. Imaging in Hepatic Veno-Occlusive Disease/Sinusoidal Obstruction Syndrome. Biol. Blood Marrow Transplant. 2020, 26, 1770-1779. [CrossRef]

31. R Core Team-European Environment Agency. 2020. Available online: https://www.eea.europa.eu/data-and-maps/indicators/ oxygen-consuming-substances-in-rivers/r-development-core-team-2006 (accessed on 23 November 2021).

32. Koo, T.K.; Li, M.Y. A Guideline of Selecting and Reporting Intraclass Correlation Coefficients for Reliability Research. J. Chiropr. Med. 2016, 15, 155-163. [CrossRef]

33. Cairo, M.S.; Cooke, K.R.; Lazarus, H.M.; Chao, N. Modified Diagnostic Criteria, Grading Classification and Newly Elucidated Pathophysiology of Hepatic SOS/VOD after Haematopoietic Cell Transplantation. Br. J. Haematol. 2020, 190, 822-836. [CrossRef]

34. McDonald, G.B. Veno-Occlusive Disease of the Liver and Multiorgan Failure after Bone Marrow Transplantation: A Cohort Study of 355 Patients. Ann. Intern. Med. 1993, 118, 255. [CrossRef] 
35. Nishida, M.; Sugita, J.; Takahashi, S.; Iwai, T.; Sato, M.; Kudo, Y.; Omotehara, S.; Horie, T.; Sakano, R.; Shibuya, H.; et al. Refined Ultrasonographic Criteria for Sinusoidal Obstruction Syndrome after Hematopoietic Stem Cell Transplantation. Int. J. Hematol. 2021, 114, 94-101. [CrossRef]

36. Ecsedi, M.; Schmohl, J.; Zeiser, R.; Drexler, B.; Halter, J.; Medinger, M.; Duyster, J.; Kanz, L.; Passweg, J.; Finke, J.; et al. AntiThymocyte Globulin-Induced Hyperbilirubinemia in Patients with Myelofibrosis Undergoing Allogeneic Hematopoietic Cell Transplantation. Ann. Hematol. 2016, 95, 1627-1636. [CrossRef]

37. Dai, H.; Penack, O.; Radujkovic, A.; Schult, D.; Majer-Lauterbach, J.; Blau, I.W.; Bullinger, L.; Jiang, S.; Müller-Tidow, C.; Dreger, P.; et al. Early Bilirubinemia after Allogeneic Stem Cell Transplantation-An Endothelial Complication. Bone Marrow Transplant. 2021, 56, 1573-1583. [CrossRef] [PubMed]

38. Franeková, J.; Sečník, P.; Lavríková, P.; Kubíček, Z.; Hošková, L.; Kieslichová, E.; Jabor, A. Serial Measurement of Presepsin, Procalcitonin, and C-Reactive Protein in the Early Postoperative Period and the Response to Antithymocyte Globulin Administration after Heart Transplantation. Clin. Transplant. 2017, 31, e12870. [CrossRef] [PubMed]

39. Fein, J.A.; Shimoni, A.; Danylesko, I.; Shem-Tov, N.; Yerushalmi, R.; Chowers, G.; Cohen, Z.; Nagler, A.; Shouval, R. Early Organ Toxicity Following Allogeneic Hematopoietic Stem Cell Transplantation Differs By Conditioning Regimen. Blood 2019, 134, 4489. [CrossRef]

40. Kaya, N. Grayscale and Spectral Doppler Ultrasound in the Diagnosis of Hepatic Veno-Occlusive Disease/Sinusoidal Obstruction Syndrome after Hematopoietic Stem Cell Transplantation in Children. J. Pediatr. Hematol. Oncol. 2021, 43, e1105. [CrossRef] [PubMed] 